\title{
Log10 International Units per Milliliter
}

National Cancer Institute

\section{Source}

National Cancer Institute. Log 10 International Units per Milliliter. NCI Thesaurus. Code C116238.

A logarithmic-scale (base 10) unit for measuring international units per unit of volume equal to one milliliter. 